\title{
Estimation of Genetic Diversity among Superior CPTs of Acacia nilotica
}

\author{
Amit Singhdoha, R.S. Dhillon and Vishal Johar* \\ Department of Forestry, CCS Haryana Agricultural University, Hiasr -125004, Haryana, India \\ *Corresponding author
}

\section{A B S T R A C T}

\begin{tabular}{|l|}
\hline Ke y w or d s \\
Acacia nilotica, \\
$\begin{array}{l}\text { Candidate Plus tree, } \\
\text { Genetic Diversity } \\
\text { and Mahalanobis D }\end{array}$ \\
statistic.
\end{tabular}

Sixty candidate plus trees (CPTs) of Acacia nilotica were selected through intensive survey among six different provenances/ geographical area. Selection was based on the characters of economic interest viz. Straightness, self-pruning ability, clear bole height, low branching habit, disease resistance. Various pod and seed parameters were collected to estimate diversity among different CPTs from various provenances. It was observed that the CPTs were distributed among seven different clusters representing diversity among each other. It was observed that Cluster I was the largest having fourteen CPTs followed by cluster V. Average intra-cluster distance was found maximum in cluster I followed by cluster IV and cluster II while, the inter cluster varied from 2.681 to 5.734 , the maximum being between cluster I and VII. The present study revealed that the hybridization between the more divergence genotypes of A. nilotica can produce genotypes with high hetrotic vigour.

\section{Introduction}

Acacia is a large woody genus comprising more than 1000 species occurring naturally all over the world. The generic name 'Acacia' comes from the greek word 'akis', meaning a barb or a point. The species Acacia nilotica (L.) Willd.ex Del belongs to family Fabaceae and commonly known as kikar or babul. According to Champion and Seth (1968), the species is growing naturally in southern tropical dry deciduous forests and southern tropical thorn forests therefore, the species is considered to be native of Indian Subcontinent, Burma, Sri Lanka, Saudi Arabia, Tropical Africa, Egypt and in West and East Sudan. The largest tracts are found in Sind. It is distributed throughout the greater part of
India in forest areas, farmlands, agriculture fields, roadsides, tank foreshores, village grazing lands, bunds, waste lands, along the railway lines and the national highways. Mostly it occurs as an isolated tree and rarely found in patches to a limited extent in forests. It has been widely planted on farms throughout the plains of the Indian subcontinent.

A. niloticais a narrow leaved, thorny, medium-sized tree with a short trunk, which attains a height up to $18 \mathrm{~m}$ and a girth up to 3 $\mathrm{m}$ in favourable environment. It is a single stemmed, evergreen tree having round spreading crown with feathery foliage. It has 
a deep and extensive root system. The bark is usually slaty green in young trees or nearly black in mature trees with deep longitudinal fissures exposing the inner grey-pinkish slash. The gum from the cuts in the bark exudes in form of ovoid tears. The tears are glossy and marked with minute fissures and are brittle in nature. The colour of the gum varies from pale yellow to black. It is soluble in water (Nadkarni, 2005). Thorns are thin, straight, light grey exist in axillary pairs (usually 312), $5-7.5 \mathrm{~cm}$ long in young trees and mature trees commonly without thorns (Mann et al., 2003). Flowers in globulous heads, $1.2-1.5 \mathrm{~cm}$ in diameter of a bright golden yellow colour, born either axillary or whorly on peduncles 2$3 \mathrm{~cm}$ long located at the end of branches. The tree produces showy bright yellow flowers that are pollinated by bees (Baravker et al., 2008).

It has adapted to wide range of climate. It thrives well in hot weather where maximum temperature as high as $50^{\circ} \mathrm{C}$ and minimum up to $0^{0} \mathrm{C}$, on the altitude up to $1500 \mathrm{~m}$. It can withstand conditions of drought however; adequate moisture is needed for full growth and development. It is frost tender when young and trees of all age classes are adversely affected by conditions of severe frost. It is fire tender and both seedlings and saplings are adversely affected by fire. The average annual rainfall varies from 250-1500 mm. (Bargali and Bargali, 2009). The species grows in different types of soil however; it prefers riverine alluvial soil and black cotton soil. It is found extensively growing on degraded saline/alkaline soils, growing on soils up to $\mathrm{pH} 9$.

The wide geographical distribution of the species indicates that there should be a wide genetic variability in $A$. nilotica that needs to be identified and analysed. Genetic diversity is the most important component of biodiversity and foundation of ecosystem stability and forest sustainability (Libby, 1973). The assessment of genetic variability is vital to tree improvement programme (Zobel, 1971). Genetic diversity helps in selecting potential parents for hybridization either to exploit heterosis or for transgressive segregates in subsequent generations. The nature and degree of divergence in phenotypically superior is useful for classifying them in to groups on the basis of their diversity, particularly when overlapping for one or more characters is frequent. $\mathrm{D}^{2}$ analysis is the most appropriate statistical tool to assess the genetic divergence quantitatively between biological populations. In the present investigation, an attempt was made to ascertain the magnitude of genetic diversity among some phenotypically superior tress using $\mathrm{D}^{2}$ analysis and to identify potential parents for $A$. nilotica tree improvement programme.

\section{Materials and Methods}

An intensive survey was conducted in six provenances/geographical locations during June 2014 for collection of Acacia nilotica quality pod (Table 1).

Randomly ten phenotypically superior candidate plus trees (CPTs) were selected from each provenance on the basis characters of economic interest viz. Straightness, selfpruning ability, clear bole height, low branching habit, disease resistance etc., keeping an isolation distance of $200 \mathrm{~m}$ having true representation of each provenance. Sufficient quantity of quality pods were collected from each tree and were kept separately in cloth bags for further study purpose. The pods from each provenance were measured randomly with help of measuring scale for the estimation of pod average length and pod width. The seeds from each pod were extracted manually and were counted to estimate the average number of 
seeds per pod. The extracted seeds were measured with the help of digital Vernier calliper to estimate average length, width and average thickness of seeds. One hundred seed weight was estimated with the help of digital balance to estimate the physical health of the seeds. Mahalanobis's $\mathrm{D}^{2}$ statistic (Malabanobis, 1936) was used for studying genetic diversity among different CPTs and for multivariate analysis. Further, desirable statistical tools were used for data analysis to obtain fruitful results (Panse and Sukhatme, 1978).

\section{Results and Discussion}

Analysis of variance suggested significant differences among the selected genotype for pod and seed characters (Table 2). The test of significance based on Wilks's criterion also showed substantial variations among the populations for the pooled effects of all the traits. This validated further $\mathrm{D}^{2}$ analysis. The dendrogram based on Euclidean distance for seed traits grouped the sixty genotypes into seven clusters at a cut of approximately 27 Euclidean distances (Figure 1).

On the basis of $\mathrm{D}^{2}$ analysis, 60 selected trees were grouped into seven clusters (Table 3). The tree distribution varied from 5 to 14 among different clusters. Clusters I was largest and accommodated fourteen trees followed by cluster $\mathrm{V}$ with 11 trees. In general, the clusters pattern specified that the diversity was not associated to ecogeographical distribution of genotypes, as the trees selected from particular locations were spread all over the clusters. Thus, the geographic diversity cannot always be taken as an index to genetic diversity as advocated by several research workers (Anand et al., 2005; Kaushik et al., 2007; Dhillon et al., 2009). It seems that the selection intensity and duration for which selection forces remained in operation were more important sources for genetic diversity among the selected trees rather than eco-geographical factors. Murthy and Arunachalam (1996) stated that genetic drift and selection intensity as well as the time, rather than geographical distance seem the basis of genetic diversity. Free exchange of seed material among the different regions is known to occur since long. Subsequently, the character constellations that might be associated with particular region, in nature, loose their distinctiveness under human interference. However, in some case effect of geographic origin influenced clustering. As the majority selected trees from Dausa provenance were grouped in cluster VII. This may be due to dependence upon the directional selection pressure that leads evolve homoeostatic devices that would favour consistency of the associated characters and thus resulting in discriminate clustering. These finding are in corroboration with those reported by Yadav et al., (2006).

Table.1 Geographical information of Acacia nilotica provenances

\begin{tabular}{|l|l|c|c|c|c|}
\hline District & State & $\begin{array}{c}\text { Latitude } \\
\left({ }^{\mathbf{0}} \mathbf{N}\right)\end{array}$ & $\begin{array}{c}\text { Longitude } \\
\left({ }^{\mathbf{0}} \mathbf{E}\right)\end{array}$ & $\begin{array}{c}\text { Altitude } \\
(\mathbf{M})\end{array}$ & $\begin{array}{c}\text { Rainfall } \\
(\mathbf{m m})\end{array}$ \\
\hline Ferozpur & Punjab & 31 & 75 & $197 \mathrm{~m}$ & $731 \mathrm{~mm}$ \\
\hline Rupnagar & Punjab & 31 & 77 & $262 \mathrm{~m}$ & $776 \mathrm{~mm}$ \\
\hline Hanumangarh & Rajasthan & 29 & 75 & $181 \mathrm{~m}$ & $241 \mathrm{~m}$ \\
\hline Sonipat & Haryana & 29 & 77 & $224 \mathrm{~m}$ & $653 \mathrm{~mm}$ \\
\hline Nagaur & Rajasthan & 27 & 75 & $295 \mathrm{~m}$ & $310 \mathrm{~mm}$ \\
\hline Dausa & Rajasthan & 27 & 77 & $342 \mathrm{~m}$ & $598 \mathrm{~mm}$ \\
\hline
\end{tabular}


Table.2 Analysis of variance for pod and seed characters of A. nilotica

\begin{tabular}{|l|c|c|c|}
\hline \multirow{2}{*}{ Characters } & \multicolumn{3}{|c|}{ Mean sum of squares } \\
\cline { 2 - 4 } & Genotype & Error & F \\
\hline Pod length & 2.204 & 0.325 & $6.77^{* *}$ \\
\hline Pod width & 1.205 & 0.194 & $6.22^{* *}$ \\
\hline Seeds/pod & 1.734 & 0.209 & $8.29^{* *}$ \\
\hline Seed length & 0.107 & 0.077 & $1.39^{*}$ \\
\hline Seed width & 0.080 & 0.030 & $2.65^{* *}$ \\
\hline Seed thickness & 0.077 & 0.037 & $2.06^{* *}$ \\
\hline Seed weight & 8.818 & 0.780 & $11.29^{* *}$ \\
\hline
\end{tabular}

**,* Significant at $1 \%$ and $5 \%$, respectively.

Table.3 Grouping of various trees into different clusters

\begin{tabular}{|c|c|l|}
\hline Cluster & Trees in cluster & Tree's accession number \\
\hline I & 14 & PF1, RH10, PF2, RH2, PR2, PF4, RH6, RH1, RH9, RN10, PF9, PF7, PR1, PF10 \\
\hline II & 8 & PF6, RH7, PF8, RH8, PR7, RN8, RN6, RN7 \\
\hline III & 7 & PF5, RH4, PF3, PR8, RH5, PR5, RH3 \\
\hline IV & 5 & PR3, PR4, HS2, HS1, PR6 \\
\hline V & 11 & PR9, HS8, HS7, HS9, HS10, PR10, HS4, HS3, HS6, RD9, HS5 \\
\hline VI & 7 & RN3, RN5, RN4, RN9, RD4, RN2, RN1 \\
\hline VII & 8 & RD2, RD7, RD6, RD10, RD1, RD3, RD8, RD5 \\
\hline
\end{tabular}

Table.4 Average intra and inter cluster distance in seven clusters of A. nilotica

\begin{tabular}{|l|c|c|c|c|c|c|c|}
\hline & Cluster I & Cluster II & Cluster III & Cluster IV & Cluster V & Cluster VI & Cluster VII \\
\hline Cluster I & 2.936 & 3.458 & 3.195 & 4.285 & 4.328 & 3.943 & 5.734 \\
\hline Cluster II & & 2.297 & 3.374 & 4.136 & 3.784 & 3.265 & 4.905 \\
\hline Cluster III & & & 1.792 & 3.249 & 3.343 & 3.926 & 4.878 \\
\hline Cluster IV & & & & 2.893 & 3.310 & 3.772 & 3.976 \\
\hline Cluster V & & & & & 1.900 & 2.681 & 2.696 \\
\hline Cluster VI & & & & & & 1.697 & 3.434 \\
\hline Cluster VII & & & & & & & 1.891 \\
\hline
\end{tabular}

Table.5 Cluster means for various traits of A. nilotica

\begin{tabular}{|c|c|c|c|c|c|c|c|}
\hline Clusters & $\begin{array}{c}\text { Pod } \\
\text { length } \\
(\mathbf{c m})\end{array}$ & $\begin{array}{c}\text { Pod } \\
\text { width } \\
(\mathbf{m m})\end{array}$ & $\begin{array}{c}\text { Seeds/ } \\
\text { pod }\end{array}$ & $\begin{array}{c}\text { Seed } \\
\text { length } \\
(\mathbf{m m})\end{array}$ & $\begin{array}{c}\text { Seed } \\
\text { width } \\
(\mathbf{m m})\end{array}$ & $\begin{array}{c}\text { Seed } \\
\text { thickness } \\
(\mathbf{m m})\end{array}$ & $\begin{array}{c}\text { Seed } \\
\text { weight } \\
(\mathbf{g})\end{array}$ \\
\hline I & 13.205 & 13.686 & 9.943 & 7.597 & 6.654 & 3.662 & 14.130 \\
\hline II & 14.144 & 12.700 & 9.863 & 7.762 & 6.784 & 3.675 & 15.486 \\
\hline III & 14.713 & 13.791 & 10.519 & 7.621 & 6.755 & 3.559 & 13.480 \\
\hline IV & 14.685 & 14.080 & 11.400 & 7.533 & 6.905 & 3.718 & 16.144 \\
\hline V & 14.988 & 14.236 & 10.548 & 7.882 & 6.943 & 3.861 & 15.265 \\
\hline VI & 14.129 & 13.914 & 9.757 & 7.845 & 6.857 & 3.886 & 17.452 \\
\hline VII & 15.219 & 14.200 & 11.438 & 8.027 & 7.014 & 3.990 & 17.150 \\
\hline
\end{tabular}


Fig.1 Dendrogram using average linkage prepared with average seed characters collected from different geographical sites

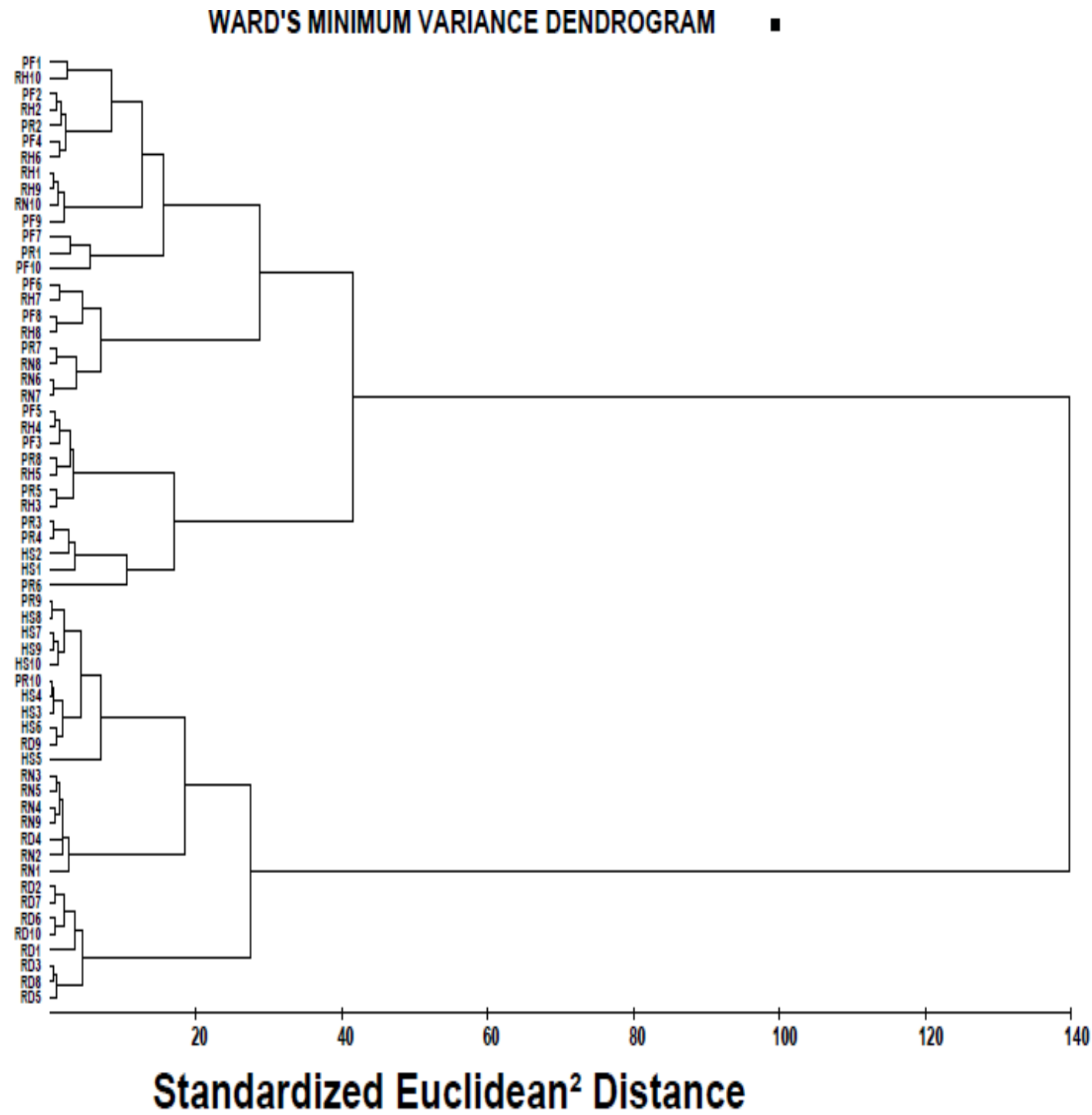

The average intra-cluster distance was maximum (2.936) in cluster I followed by cluster IV (2.893) and cluster II (2.297) (Table $4)$. Considerable diversity among these trees appears to occur. The inter cluster $\mathrm{D}^{2}$ value varied from 2.681 to 5.734 , the maximum being between cluster I and VII followed by cluster II and VII (4.905) and cluster III and VII (4.878). Thus, the maximum diversity was found between the trees belonging to these clusters. Hybridization between genotypes from these clusters is expected to yield heterotic crossbreeds. The results of present study are also in line with the findings of other research workers in other tree species viz. Prosopis cineraria and Bauhinia variegata (Anand et al., 2005; Manga and Sen, 2000). The minimum distance (2.681) between clusters V and VI revealed that the trees belonging to these clusters were genetically closer.

The cluster means for different characters under study showed considerable genetic differences between groups (Table 5). Cluster VII had maximum pod length, number of seeds per pod, seed length, seed width, seed thickness and second highest in pod width and seed weight. Whereas, cluster $\mathrm{V}$ exhibited maximum pod 
width and cluster VI registered highest seed weight among the clusters. Overall, Cluster VII and $\mathrm{V}$ showed high mean performance for most of the traits. Hence, the genotypes belonging to this cluster were divergent as well as had higher mean for most of important seed traits. Therefore, hybridization involving trees clusters VII and V is advocated in order to achieve high yielding genotypes of $A$. nilotica.

The results of the present study revealed that the geographical diversity is not the only index in determining divergence but the selection of genotype should be based on genetic diversity. The hybridization between the more divergence genotypes of A. nilotica can produce genotypes with high heterotic vigour.

\section{References}

Anand, R.K., Chauhan, K.C. and Huse, S.K. 2005.Genetic divergence studies in plus tree families of Bauhinia variegate Linn.for its growth and biomass traits. Multipurpose trees in the Tropics: Management and Improvement Strategies (Tiwari, V.P. and Srivastava, R.L., Eds). AFRI, Jodhpur (India). Pp. 744-748.

Baravker, A.A., Kale, R.N., Patil, R.N. and Sawant, S.D. 2008. Pharmaceutical and biological evaluation of formulated cream of methanolic extract of Acacia nilotica leaves. Research Journal of Pharmacology and Technology, 4: 481483.

Bargali, K., and Bargali, S.S. 2009. Acacia nilotica: a multipurpose leguminous plant. Nature and Science, 7(4): 11-19.

Champion, H.G., and Seth, S.K. 1968. A revised survey of the forest type of India. New Delhi: Govt. of India Press.

Dhillon, R.S., Verma, R.C., Dhanda, S.K.,
Sheokand, R. and Kumari, S. 2009. Genetic divergence based on quantitative variation for some seed traits in plus trees of Neem (Azadirachta indica A. Juss). Indian Journal of Agroforestry, 11(1): 5560.

Kaushik, N., Nautiyal, S., Kaushik, J.C. and Beniwal, R.S. 2007. Divergence studies in plus tree of Neem (Azadirachta indica), Indian Journal of Agroforestry, 9(2): 106-110.

Libby, W.J., 1973. Domestication strategies for forest trees. Can. J. For. Res.3: 265-276.

Mahalanobis, P.C. 1936. On the generalized distance in statistics. Proc. Nat. Inst. Sci., India 2: 49-55.

Manga, V.K., and Sen, D.N. 2000.Genetic diversity among different genotypes of Prosopis cineraria Druce. Indian Journal of Forestry, 33(3): 291-295.

Mann, A., Gbate, M. and Umar, A. 2003.Medicinal and Economic plants.Jube Evans Books and Publication, Bida, Nigeria, 160.

Murthy, B.R., and Arunachalam, V. 1996. The nature and divergence in relation to breeding system in some crop plants. Indian J. Genet.26: 188-198.

Nadkarni, A.K., 2005. Popular Prakashan Pvt. Ltd.; Mumbai, India. Dr. K. M. Nadkarani's Indian Materia Medica.

Panse, V.G., and Sukhatme, P.V. 1978. Statistical methods for agricultural workers. ICAR Publication. New Delhi.

Yadav, D.K., Pawar, I.S., Sharma, G. R. and Lamba, R.A.S. 2006. Genetic divergence in some germplasm lines of bread wheat. Natnl. J. Pl. Improv. 8 (2): 138-141.

Zobel, B.J., 1971. The genetic improvement of southern Pines. Science American, 225: 94-103.

\section{How to cite this article:}

Amit Singhdoha, R. S. Dhillon and Vishal Johar. 2017. Estimation of Genetic Diversity among Superior CPTs of Acacia nilotica. Int.J.Curr.Microbiol.App.Sci. 6(10): 1197-1202. doi: https://doi.org/10.20546/ijcmas.2017.610.144 